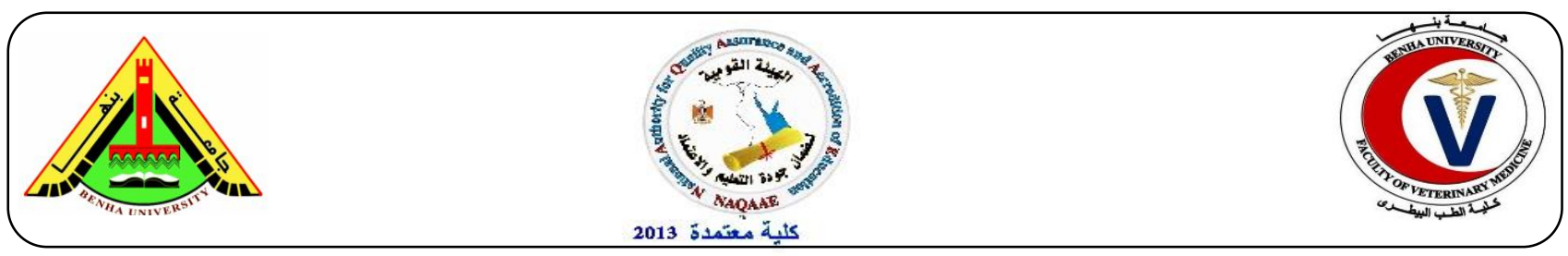

\title{
Protective Effect of Garlic Against Lipopolysaccharides-induced acute Liver damage in Mice
}

\author{
Mona A. El Shemy1,*, Ayman Samir Farid ${ }^{1}$
}

1 Department of Clinical Pathology, Faculty of Veterinary Medicine, Benha University, Moshtohor, Toukh 13736, Qalyubia, Egypt

*Corresponding: Mona Abd El-Zaher El Shemy (DVM, MVSc, PhD)

E. mail: Mona.Alshemy@fvtm.bu.edu.eg

\section{A B S T R A C T}

Lipopolysaccharides (LPSs) are strong hepatotoxin that is used to induce oxidative liver damage in the experimental animal model. This study aimed to investigate how the antioxidant properties of garlic are able to protect against LPSs-induced hepatic damage in mice. Forty male albino mice were divided into 4 equal groups; Control, Garlic, LPS and garlic protected group. LPSs was administered at a dose of $3 \mathrm{mg} / \mathrm{kg}$ b.wt once intraperitoneally and garlic was given intragastric at a dose of $500 \mathrm{mg}$ $/ \mathrm{kg}$ body weight dissolved in distilled water once daily for three weeks. LPSs induced a significant liver injury manifested by significant increased serum ALT and AST activities and total bilirubin concentration accompanied by significant decreased serum albumin and total proteins levels. Also, LPSs induced a significant increase in the level of hepatic malondialdehyde (MDA). Moreover, it induced a depletion in the antioxidant status manifested by reduction of hepatic glutathion (GSH), glutathion peroxidase (Gpx) and super oxide dismutase (SOD) in the liver homogenate. LPSs induced a microcytic hypochromic anemia with significant decrease in total leukocytic and lymphocytic count. The examined hepatic tissue revealed karyomegalocytes with ballooning degeneration and fibrosis in portal area. On the other hand, garlic alleviated the liver damage caused by LPSs. It was concluded that the anti-oxidant properties of garlic powder are effective in reversing the LPSs oxidant hepatic damage in mice.

Keywords: Garlic, LPSs, antioxidant enzymes, hepatitis.

\section{INTRODUCTION}

Lipopolysaccharides (LPSs) are the component of the outer membrane of Gram ve bacteria formed from glycolipid. It is called endotoxins. It causes sepsis and liver injury in animals and humans (Opal 2007).
LPSs administration stimulates macrophage to produce free radicals that cause oxidative damage to the tissues and organs. Hepatic Kupffer cells are the main cells for LPSs detoxification. LPSs sepsis affects all organ 
functions through the oxidative stress and reactive oxygen species (ROS) production that cause the damaging and harmful effects of LPSs. Sepsis needs intensive care and attention as it causes dysfunction of organs and may cause death (Vasanth etal.,2018). The severity of this oxidative tissue damage depends on the anti-oxidant status of the body. The imbalance between the antioxidant status of the body and ROS production induce oxidative stress. So the usage of antioxidant substance in our daily life must be considered (Hamesch et al., 2015).

Garlic (Allium sativum) is a strong antioxidant substance that is widely used as a food additive spice (Bhandari 2012). Garlic may be used as a liquid preparation either oil, aqueous or solvent extracts or may be used as a solid form like dried garlic powder or fresh bulbs (Rodrigo et al., 2015). The powder form of garlic cotains alliin and diallyl disulfide that are responsible for the therapeutic effects of garlic (Ghalehkandi et al., 2013). Alliin interacts with allinase enzyme that is produced after crushing or chopping of garlic to produce allicin, the active biological compound of garlic (Fridman et al., 2014). Garlic contains sulfur compounds and nonsulfar compounds as polyphenols that are responsible for garlic antioxidant activity. Garlic is reported to exhibt anti-inflammatory, anti-carcinogenic, anti-microbial and anti-oxidant activities (Eilat-Adar et al., 2013). Therefore, we designed this study to evaluate how the antioxidant properties of garlic protect against the LPS injurious hepatic damage in mice.

\section{MATERIALS AND METHODS}

\subsection{Laboratory animals:}

Forty male albino mice were taken from the Experimental unit, Faculty of Veterinary Medicine, Benha University, Egypt. All animals were separated in clean cages. All over the period of the experiment, all animals were kept at suitable environment and nutritional condition.

\subsection{Chemicals:}

Lipopolysaccharide (LPSs) (Sigma-Aldrich Chemical, USA) was administered at a dose of (3 $\mathrm{mg} / \mathrm{kg}$ body weight) dissolved in phosphate buffer saline at a single dose intraperitoneally according to Vasanth et al., (2018). Garlic (Garlic; Powder from local market) was taken orally (500 mg garlic $/ \mathrm{kg}$ body weight) dissolved in distilled water and administered by the stomach tube once daily for three weeks according to Ezeala etal. (2008).

\subsection{Experimental design}

Animals were divided randomly into four groups (10 animals/group): group I (control group); group II (LPS group) that administered $3 \mathrm{mg} / \mathrm{kg} \quad$ b.wt once intraperitoneally (Vasanth et al., 2018); group III (Garlic group) was received garlic orally (500 mg garlic/kg b.wt) once per day for three weeks according to Ezeala et al., (2008); and group IV (Garlic protected group) was administered garlic by oral route once daily for three weeks (500 mg garlic/kg b.wt ) then a single dose of LPS was given intraperitoneally (3 $\mathrm{mg} / \mathrm{kg}$ b.wt).

\subsection{Sampling:}

Blood samples for serum separation and hepatic specimens were taken from all animals after 24 hours of LPS administration for estimation of hepatic injury markers, oxidative stress parameters, antioxidant biomarkers in addition to the histopathological examination of liver tissue. 
Blood samples from the retro-orbital venous plexus were collected then hepatic tissues were taken after scarification. Blood was putted into 2 tubes: plain tube to collect serum for estimation of alanine amino transferase (ALT) and aspartate amino transferase (AST) activities, as well as total bilirubin (TB), total proteins (TP) and albumin concentrations, while the other tube on EDTA for hematological examination.

The liver tissue specimens (1 gm of hepatic tissue) was washed and homogenized 10\% (Weight of liver tissue, g per Volume of the buffer, $\mathrm{mL}$ ). The homogenate was centrifuged at $4000 \mathrm{rpm}$ for $5 \mathrm{~min}$ at $4^{\circ} \mathrm{C}$. The clear homogenate was stored at $-20^{\circ} \mathrm{C}$ for determination of the activities of glutathione peroxidase (GPx), reduced glutathione (GSH) and superoxide dismutase (SOD) in addition to malondialdehyde (MDA).

\subsection{Histopathological examination:}

Autopsy samples were taken from the liver of mice in different groups and fixed in 10\% formalin saline for 24 hours. Washing and dehydration was done. The specimens were cleared then embedded in paraffin at $56^{\circ}$ for 24 hours. The blocks of paraffin were prepared for sectioning. The obtained tissue sections were collected on glass slides, deparaffinized then stained by hematoxylin \&eosin stain for routine examination through the light electric microscope (Banchroft et al., 1996).

\subsection{Biochemical analysis:}

2.6.1.Estimation of serum ALT and AST activities, Total bilirubin, Total protein and Albumin

Activities of serum ALT, AST, total bilirubin, total protein and albumin levels were done by kits from Diamond Diagnostics, Egypt in accordance with the manufacturer instructions.

\subsubsection{Estimation of hepatic glutathione} peroxidase activity (GPX), (GSH), (MDA) and (SOD)

hepatic glutathione peroxidase activity (GPx), (GSH), (MDA) and (SOD) were determined according to the methods described by Paglia and Valentine (1967), Sedlak and L'Hanus (1982), Ohkawa, Ohishi, and Yagi 1979 and Misra \& Fridovich 1972, respectively.

\subsection{Statistical Analysis:}

It was done by using the statistical software package SPSS for Windows (Version 16.0; SPSS Inc., Chicago, Ill). The significance of differences between more than two groups was estimated by ANOVA. Results are expressed as the mean \pm SEM. The $P$-value of less than 0.05 was considered significant (Kinnear and Gray 2006).

\section{RESULTS}

\subsection{Hematological parameters:}

LPS administration induced a state of microcytic hypochromic anemia which is manifested by a significant decrease in $\mathrm{RBCs}, \mathrm{Hb}$ concentration, hematocrit value, mean corpuscular volume and mean corpuscular hemoglobin concentration in relation to control group and garlic group. Garlic administration showed non-significant change in $\mathrm{RBCs}, \mathrm{Hb}$ concentration, hematocrit value, mean corpuscular volume and mean corpuscular hemoglobin concentration when compared to control group. In the garlic protected group, there was a significant increase in $\mathrm{RBCs}, \mathrm{Hb}$ concentration and hematocrit value, mean 
corpuscular volume and mean corpuscular hemoglobin concentration in comparison with LPS group. When comparing garlic protected group to control group, there were non-significant changes in RBCs count and mean corpuscular hemoglobin concentration with significant reduction in $\mathrm{Hb}$, hematocrit value and mean corpuscular volume (Table $1)$.

In LPS group, there were significant reduction in WBCs and lymphocyte with significant increase in monocyte count in relation to control group and garlic group. The garlic group showed a non-significant change in WBCs, lymphocytic and monocytic counts when compared to control group. In garlic protected group, there was significant increase in WBCs, lymphocyte with significant decrease in monocyte counts in comparison with LPS group. Meanwhile, when garlic protected group was compared to control group, it showed significant decrease in WBCs, lymphocyte and monocyte counts. (Table 2).

\subsection{Serum ALT, AST, Total bilirubin, TP and albumin:}

The LPS group had significant increased values of serum ALT, AST and total bilirubin associated with significant reductions in serum total proteins and albumin levels when compared to control group and garlic group. Garlic group showed a non-significant change of serum ALT, AST, TB, total protein and albumin in comparison with control group. With respect to the garlic protected group, it showed significant decrease in ALT, AST and TB with significant increase in serum total protein and albumin when compared to LPS group. Meanwhile, when the garlic protected group compared to control group, it showed significant increase in serum ALT and AST with a nonsignificant change in serum total proteins and albumin levels and non-significant difference in serum TB. (Table 3).

\subsection{Hepatic MDA, GSH, GPx and SOD activity}

There was depletion of antioxidant enzymes with a state of oxidative stress that was manifested by significant reduction of the liver GSH, GPx and SOD activities with significant elevation of hepatic MDA in relation with control group and garlic group. There was no significant difference in liver GPx, SOD and MDA levels with significant elevation in the level of GSH in garlic group when compared to control group. Garlic protected group showed a significant increase in GSH, GPx and SOD activities with a significant decrease in hepatic MDA when compared to LPS group. On the other hand, when garlic protected group was compared to control group, it showed a significant decrease in GSH and GPx with significant increase in hepatic MDA and no significant change in SOD level. (Table 4).

\subsection{Histopathological examination of hepatic tissue}

The examined hepatic sections in LPS group showed fatty change in diffuse manner in the hepatocyte associated with inflammatory cells infiltration and fibrosis in the portal area (Figure 1. B). The bile duct in the portal area showed hyperplasia with periductal fibrosis and inflammatory cells infiltration (Figure 1.C). Focal areas in the hepatic parenchyma showed karyomegalocytes and ballooning degeneration. (Figure 1.D). While, in garlic protected group, there was periductal inflammatory cells infiltration surrounding the bile ducts associated with congestion of portal vein in the portal area (Figure 1.F). No 
histopathological alterations and the normal histological structure of the central vein and surrounding hepatocytes in the parenchyma were recorded in control (Figure 1.A) and garlic (Figure 1.E) groups.

\section{DISCUSSION}

LPSs-induced sepsis and hepatotoxicity is a life threating problem all over the world. The administration of LPSs stimulates the production of reactive oxygen species and nitric oxide that causes organ failure, tissue injury and inflammatory response (Wang et al.,2009). Garlic is a common medicinal plant that is widely utilized. It contains many medically active substances like sulfur compounds which are vasoactive substances that initiate the formation of cardioprotective cell-signaling substance by red blood cells (Ghalehkandi et al., 2013; Benavides et al., 2007). The present study proved the disturbance in the anti-oxidant status of the liver of mice after the endotoxic shock induced by LPSs. Also, the protective role of garlic against LPS-induced injury had been reported.

LPSs in this study induced a state of microcytic hypochromic anemia which is reflected by reduction in the RBCs count, hemoglobin concentration, PCV, MCV and MCHC when compared to control group. It is due to the destruction of the mature RBCs and the reduction in the rate of erythropoiesis. The LPSs-induced effects on RBCs, hemoglobin concentration and hematocrit matched with Huang et al., (2017); Brendth et al., (2012). In addition, LPSs induced a significant decrease in the WBCs, lymphocyte and monocyte count if it is compared to control group. The immunosuppressive effects of LPS coincided with Shin et al., (2007) and Kurhaluk et al.,
(2018) who recorded that the LPSs administration induced a significant decrease in WBCs count which may be due to migration of neutrophils and macrophages from blood to the affected tissue resulting in an immunosuppression state. The lymphopenia occurred as a result of exhaustion of lymphocytes as a result of apoptosis and excessive production of cytokines after lymphocytic stimulation induced by LPSs administration. (Monneret and Venet, 2012). In this study, the administration of garlic at a dose of $500 \mathrm{mg}$ garlic / $\mathrm{kg}$ body weight dissolved in distilled water for three weeks before LPS administration (garlic protected group) resulted in a significant increase in the RBCs count, hemoglobin concentration, PCV, MCV and MCHC when compared to LPS group. It may be due to the presence of constituents in garlic that compete with $\mathrm{HB}$ in the RBCs for oxygen resulting in a state of hypoxia. This garlic induced hypoxic state stimulates erythropoiesis. These results agreed with Tende et al. (2014); Samson et al., (2012). Moreover, garlic induced a significant increase in total leukocytic and lymphocytic count in garlic protected group in comparison with LPS group. This is due to the immunostimulant effect of garlic. The results of this study matched with Tende et al. (2014); Bjarnsholt et al. (2005). Meanwhile, when garlic protected group was compared to control group it showed significant decrease in WBCs, lymphocytic and monocytic count and not reached to the normal value that may be due to excessive migration of neutrophils and macrophages from blood to the affected tissue in response to LPSs administration.

Administration of LPSs in mice $3 \mathrm{mg} / \mathrm{kg}$ b.wt once intraperitoneally caused hepatic 
damage. This is reflected by significant elevation in serum hepatocellular injury enzymes (ALT and AST) and total bilirubin with significant reduction in serum total protein and albumin than the control group. These findings are in an agreement with Vasanth et al., et al. (2018); Omar et al. (2010). The hepatic cell destruction may have occurred due to the effect of the flooded inflammatory cytokines that are produced from neutrophils and monocytes in response to LPSs administration. These cytokines induced a damage to the hepatocytes and resulted in organ disturbance. Moreover, this hepatic cell destruction may also be due to excessive reactive oxygen and nitrogen species production with super oxide and nitric oxide anions after LPSs administration that accelerate the damage to the hepatocyte membrane (Kaur et al., 2006; Sang et al., 2010). The hepatic injury is confirmed by histopathological examination of the liver tissue after administration of LPSs which revealed fatty change in diffuse manner in the hepatocyte associated with inflammatory cells infiltration and fibrosis in the portal area (Figure 1.B). The bile duct in the portal area showed hyperplasia with periductal fibrosis and inflammatory cells infiltration (Figure 1.C). Focal areas in the hepatic parenchyma showed karyomegalocytes and ballooning degeneration. (Figure 1.D). Regarding the hepatic MDA in LPS group, there was significant elevation in MDA level when compared to control group which ascertains the occurrence of liver oxidative stress injury. This result matched with Vasanth et al., (2018) and Minutoli et al., (2008) who recorded the LPS- induced lipid peroxidation which occurred as a result of formation of the powerful oxidant (peroxynitrite) that damages the biological membrane molecules and causes the oxidative stress damage. Furthermore, there was a significant decrease in the hepatic SOD, GSH, GPx in LPS group compared to control group. Glutathione serves as a protective element against the toxic metabolites. It maintains the redox state of the cell. The LPSs caused glutathione depletion that induced oxidative stress. The SOD and GPx activities are considered as the first line of anti-oxidant defense system in the body as they respectively dismutate super oxide radicals which are elicited in normal body metabolism. The depletion of these antioxidant enzymes resulted in oxidative tissue injury. Vasanth et al. (2018); Kaur et al. (2006); El Kamouni et al. (2017) and Karuppanapandian et al. (2011).

Administration of garlic induced a significant reduction in the activities of serum ALT, AST and total bilirubin levels with a significant increase in serum albumin and total proteins level when compared to LPS group. This ascertains the hepatoprotective effects of garlic against the damaging effect of LPSs on the liver. Our result was confirmed with histopathological examination of liver tissue of garlic group that showed normal histological structure of the central vein and surrounding hepatocytes in the parenchyma (Figure E). These results coincide with Duvvu et al., (2018); Ezeala et al., (2008); Tende et al.,(2014). Meanwhile, when garlic protected group compared to control group, the serum ALT, AST showed a significant increase than the control group. The albumin and total proteins levels showed significant decrease in comparison with control group. Which is supported by histopathological examination of hepatic tissue section that reviled periductal inflammatory cells infiltration surrounding the bile ducts associated with congestion of portal vein in the portal area (Figure F). This ascertains that garlic protected the liver cell from damage, but the 
function of liver cells was not fully returned. Moreover, these results confirmed that garlic has a powerful anti-oxidant effect that reduced the LPS-induced elevated hepatic MDA level and significantly elevated the hepatic glutathione, glutathione peroxidase and SOD levels. These results in agreement with the results of El-Shafey et al., (2013); Yousef et al., (2015) who said that garlic has high amounts of phytochemicals (S-allyl-Lcysteine and S-allyl mercaptocystein) that elevate the level of these hepatic anti-oxidant enzymes which detoxify free radicals and prevent the hepatocellular injury. The degree of hepatic injury depends on the concentration of antioxidant enzymes. (Badr and Al-Mulhim, 2014)

\section{CONCLUSION}

Garlic alleviate the LPS- induced hepatotoxicity, oxidative stress and immunodeficiency via improving the antioxidant activities. So, we recommend the daily utilization of garlic to enhance antioxidant enzyme system and to protect against septic shock and liver injury.

\section{REFERENCES:}

Badr GM and Al-Mulhim JA 2014. The protective effect of aged garlic extract on nonsteroidal anti-inflammatory drug-induced gastric inflammations in male albino rats. Evidence-Based Complementary and Alternative Medicine 9. Doi 10.1155.

Banchroft, JD, Stevens A and Turner DR 1996. Theory and Practice of Histological Techniques. Fourth Ed. Churchil Livingstone, New York, London, San Francisco, Tokyo.

Benavides GA, Squadrito GL, Mills RW, Patel HD, Isbell TS, Patel RP, Darley-
Usmar VM, Doeller JE and Krans DW. 2007 Hydrogen sulfide mediates the vasoactivity of garlic. Proceedings of the National Academy of Science of the U.S.A. 104: 7977-7982.

Bhamdari P 2012. Garlic (Allium sativum L.) A review of potential Therapeutic applications. Int. J. Green Pharm 6 (2): 118-129.

Bjarnsholt T, Ostrup JP,Rasmussen TB, Christophersen L, Calum H, Hougen HP,Rygaard J, Mosenn C, Ebert L, Hhalby N and Gisvkovs NM. 2005 Garlic blocks quorum sensing and promotes rapid clearing of pulmonary pseudomonas aeruginosa infections. Microbiolgy 151: 3878-3880.

Brendth P, Rehfeld I, Kamphausen A, Kreissig C and Peters J. 2012 Lipopolysaccharide interference in erythropoiesis in mice. Anaesthesia 67: 493-500.

Duvvu MV, Rao KA, Seshaiah CV and Kumar DS. 2018 Effect of Garlic supplementation on Blood Biochemical profile of Murrah Buffalo calves. Int. J. Curr. Microbiol. App. Sci. 7(3): 2973- 2983.

Eilat-Adar S, Sinai T, Yosefy C and Henkin Y. 2013 Recommendations for cardiovascular disease prevention. Nutrients 5 (9): 3646-3683.

El Kamouni S, El Keddaj R, Andreoletti P, El Ktaibi A, Rharrassi I, Essamadi A, et al., 2017 Protective Effect of Argan and Olive Oils against LPS-Induced Oxidative Stress and Inflammation in 
Mice Livers. Int. J. of Mol. Sci.18: 2181-96.

El-Shafey AM, Seddek MN, El-Ezaby MM, Seliem MM and Abd El-Maksoud MA. 2013 Protective effects of garlic (Allium Sativum) and Karkada (Hibiscus sabdarrifa) on ACRylamide Treated male Albino Rats. Egypt. J. Exp. Biol. 9 (1): 101- 107.

Ezeala C, Uno JK, Nweke I, Unekwe P, ELSafty I and Nwaegerue E. 2008. Fresh Garlic Extract Protects The Liver Against Acetaminophen-Induced Toxicity. The Internet $J$ of Nut.and Wellness 7 (1): 1 -7.

Fridman S, Sinai T and Zilberg D. 2015 Efficacy of garlic based treatments against monogenean parasites infecting the guppy (Poecilia reticulata peters). Veterinary Parasitology 203 (2): 51-58.

Ghalehkandi JG, Ebrahimnezhad Y and Sis NM 2013. The effect of aqueous garlic extract and chromium chloride complement on tissue antioxidant system of male rats. J Anim Plant Sci. 23: $56-59$.

Hamesch K, Borkham-Kamphorst E, Strnad $\mathrm{P}$ and Weiskirchen R. 2015 Lipopolysaccharide-induced inflammatory Liver injury in mice. Laboratory Animals 49 (51): 37-46.

Huang P, Wang J, Lin X, Yang F, Tand JH. 2017 Effect of IL-10 on iron metabolism in LPS-induced inflammatory mice via modulatory hepcidin expression. European Review for Medical and
Pharmacological Science 21: 34693475.

Karuppanapandian T, Moon JC, Kim C, Manoharan K and Kim W. 2011 Reactive oxygen species in plants: their generation, signal transduction and scavenging mechanisms. Aust $J$ Crop Sci. 5: 709.

Kaur G, Tirkey N and Chopra K. 2006 Beneficial effect of hesperidin on lipopolysaccharide-induced hepatotoxicity. Toxicology 226: 15260.

Kinnear, Paul, and Colin Gray. 2006. SPSS 12 made simple: Psychology press.

Kurhaluk N, Zaitseva OV, Sliuta A, Kyriienko S and Winklewski PJ 2018 Melatonin diminishes oxidative stress in plasma, retains erythrocyte resistance and restores white blood cell count after low-dose lipopolysaccharide exposure in mice. General Physiology and Biophysic 37 (5): 571-580.

Minutoli L, Altavilla D, Bitto A, Polito F, Lagana G, Fiumara T, et al. 2008 A biophysics approach to modulate the inflammatory response during endotoxic shock. Eur J Pharmacol 589: 272-80.

Misra HP, Fridovich I. 1972 The role of superoxide anion in the autoxidation of epinephrine and a simple assay for superoxide dismutase. Journal of Biological chemistry. 247 (10):31703175. 
Monneret G and Venet F. 2012 Arapidly progressing lymphocyte exhaustion after sever sepsis. BMC J. 16:140.

Ohkawa, Hiroshi, Nobuko Ohishi, and Kunio Yagi. 1979. Assay for lipid peroxides in animal tissues by thiobarbituric acid reaction. Analytical biochemistry 95 (2):351-8.

Omar ME, Abdel-Salam E, Rehab FA, Amany AS and Abdel RF. 2012 Modulation of Lipopolysaccharideinduced oxidative stress by capsaicin. Inflammopharmacol 20: 207-17.

Opal SM 2007. The host response to endotoxin, antilipopolysaccharide strategies, and the management of severe sepsis. Int J Med Microbial. 297 (5): 365-77.

Paglia DE and Valentine WN 1967. Studies on the quantitative and qualitative characterization of erythrocyte glutathione peroxidase. J. Lab. Clin. Med 70 :158-169.

Rodrigo A, Saray QF, Rocio LR, Enrique OF, Juan PR, Lucrecia CQ and Daniel OS. 2015 Immunomodulation and Anti-inflammatory Effects of Garlic Compounds. I Immunol Res Article ID 401630, 13 pages.

Samson ES, Olasunkanmi AK, Joel JS and Alfred EF. 2012 Hematological and Hepatotoxic potential of onion (Allium copa) and garlic (Allium sativum) Extracts in Rats. European J. of Medicinal plants. 2 (4): 290-307.
Sang SY, Sung PK, Mi YK and Seok HN. 2010 Inhibitory effect of curcumin on liver injury in murine model of endotoxemic shock. Biotechnol. Lett. 32: 209-14.

Sedlak J and L' Hanus. 1982. Changes of glutathione and protein bound $\mathrm{SH}$ groups concentration in rats adrenals under acute and repeated stress. Endocrinol Exp 16 (2):103-109.

Shin HH, Lee JE and Choi HS. 2007 Absence of 4-1BB increases cell influx into the peritoneal cavity in response to LPS stimulation by decreasing macrophage IL-10 levels. FEBS Lett 581: 4355-60.

Tende JA, Ayo JO, Mohammed A and Zezi AU. 2014 Effect of garlic (Allium sativum) and ginger (Zingiber officinale) extracts on haematobiochemical parameters and liver enzyme activities in wistar rats. Int. J. of food and Sci. 3 (5): 380-386.

Vasanth KT, Hanuman TM, and Prabhakar BT 2018. Protective Effects of dietary curcumin and capsaicin on LPSInduced Inflammation in mice. Pharmacognosy J. 10 (4):725-729.

Wang H, Xu T and Lewin MR. 2009 Future possibilities for the treatment of sepsic shock with herbal components. Am J Emerg Med 27: 107-12.

Yousef AE, Abdel Hakim $\mathrm{T}$ and Thakeb MM. 2015 The antioxidant effect of garlic powder on rats treated by different doses of chromium chloride. Egypt. J. Chem. Environ. Health. 1(1): 379- 388.

Table 1: Effect of pretreatment with garlic on LPSs - induced changes in Erythrogram in mice.

\begin{tabular}{|lllll|}
\hline Parameters & Control & LPS & Garlic & Garlic + LPS \\
RBCs $\left(10^{6} / \mu \mathrm{L}\right)$ & $08.70 \pm 0.26^{\mathbf{b}}$ & $06.80 \pm 0.03^{\mathbf{a}}$ & $09.06 \pm 0.08^{\mathbf{b}}$ & $08.10 \pm 0.26^{\mathbf{b}}$ \\
\hline
\end{tabular}




\begin{tabular}{|lllll|}
\hline $\mathrm{Hb}(\mathrm{g} / \mathrm{dL})$ & $12.56 \pm 0.32^{\mathbf{c}}$ & $07.00 \pm 0.57^{\mathbf{a}}$ & $12.80 \pm 0.17^{\mathbf{c}}$ & $11.46 \pm 0.31^{\mathbf{b}}$ \\
$\mathrm{PCV}(\%)$ & $44.26 \pm 1.10^{\mathbf{c}}$ & $29.41 \pm 0.50^{\mathrm{a}}$ & $45.90 \pm 0.75^{\mathbf{c}}$ & $39.36 \pm 2.03^{\mathbf{b}}$ \\
$\mathrm{MCV}(\mathrm{fL})$ & $50.80 \pm 0.29^{\mathbf{c}}$ & $42.70 \pm 0.23^{\mathbf{a}}$ & $50.56 \pm 0.39^{\mathbf{c}}$ & $48.40 \pm 1.02^{\mathbf{b}}$ \\
$\mathrm{MCHC}(\mathrm{g} / \mathrm{L})$ & $28.40 \pm 1.40^{\mathbf{b}}$ & $23.70 \pm 0.16^{\mathbf{a}}$ & $27.80 \pm 0.57^{\mathbf{b}}$ & $29.20 \pm 1.60^{\mathbf{b}}$ \\
\hline
\end{tabular}

Means values with different superscripts within the same row were significantly different at $(\mathrm{p} \leq$ 0.05) (Mean \pm S.E.M) $(n=10)$.

Table 2: Effect of pretreatment with garlic on LPSs - induced changes in Leukogram in mice.

\begin{tabular}{|lllll|}
\hline Parameters & Control & LPS & Garlic & Garlic + LPS \\
WBCs $\left(10^{3} / \mu \mathrm{L}\right)$ & $04.36 \pm 0.20^{\mathbf{c}}$ & $02.26 \pm 0.10^{\mathbf{a}}$ & $04.53 \pm 0.30^{\mathbf{c}}$ & $03.56 \pm 0.20^{\mathbf{b}}$ \\
Lymphocyte $\left(10^{3} / \mu \mathrm{L}\right)$ & $03.56 \pm 0.08^{\mathbf{c}}$ & $01.36 \pm 0.03^{\mathbf{a}}$ & $03.70 \pm 0.03^{\mathbf{c}}$ & $02.80 \pm 0.05^{\mathbf{b}}$ \\
Granulocytes $\left(10^{3} / \mu \mathrm{L}\right)$ & $00.40 \pm 0.08^{\mathbf{a}}$ & $00.44 \pm 0.02^{\mathbf{a}}$ & $00.40 \pm 0.05^{\mathbf{a}}$ & $00.40 \pm 0.08^{\mathbf{a}}$ \\
Monocyte $\left(10^{3} / \mu \mathrm{L}\right)$ & $00.39 \pm 0.50^{\mathbf{b}}$ & $00.46 \pm 0.50^{\mathbf{c}}$ & $00.38 \pm 0.30^{\mathbf{b}}$ & $00.36 \pm 0.30^{\mathbf{a}}$ \\
\hline
\end{tabular}

Means values with different superscripts within the same row were significantly different at $(\mathrm{p} \leq$ 0.05) (Mean \pm S.E.M) $(n=10)$.

Table 3. Effect of pretreatment with garlic on LPSs - induced changes in serum ALT, AST, Total Bilirubin (TB), Total Protein and Albumin in mice.

\begin{tabular}{|lllll|}
\hline Parameters & Control & LPS & Garlic & Garlic + LPS \\
ALT (U/L) & $85.20 \pm 1.20^{\mathbf{a}}$ & $138.20 \pm 1.50^{\mathbf{c}}$ & $86.33 \pm 1.10^{\mathbf{a}}$ & $91.40 \pm 0.55^{\mathbf{b}}$ \\
AST(U/L) & $89.36 \pm 0.52^{\mathbf{a}}$ & $183.26 \pm 1.40^{\mathbf{c}}$ & $88.96 \pm 0.74^{\mathbf{a}}$ & $97.26 \pm 0.52^{\mathbf{b}}$ \\
TB (mg/dl) & $00.77 \pm 0.01^{\mathbf{a}}$ & $002.77 \pm 0.01^{\mathbf{b}}$ & $00.83 \pm 0.03^{\mathbf{a}}$ & $00.88 \pm 0.03^{\mathbf{a}}$ \\
TP (g/dl) & $04.50 \pm 0.23^{\mathbf{b}}$ & $002.60 \pm 0.15^{\mathbf{a}}$ & $04.10 \pm 0.11^{\mathbf{b}}$ & $03.70 \pm 0.08^{\mathbf{b}}$ \\
Albumin (g/dl) & $02.60 \pm 0.15^{\mathbf{c}}$ & $001.30 \pm 0.11^{\mathbf{a}}$ & $02.60 \pm 0.26^{\mathbf{c}}$ & $01.93 \pm 0.08^{\mathbf{b}}$ \\
\hline
\end{tabular}

Means values with different superscripts within the same row were significantly different at $(\mathrm{p} \leq$ 0.05) (Mean \pm S.E.M) $(n=10)$.

Table 4. Effect of pretreatment with garlic on LPSs - induced changes in Liver MDA, GSH, GPX and SOD in mice.

\begin{tabular}{|lllll|} 
Parameters & Control & LPS & Garlic & Garlic + LPS \\
MDA (nmol/g) & $32.80 \pm 1.50^{\mathrm{a}}$ & $90.07 \pm 0.88^{\mathrm{c}}$ & $31.10 \pm 0.65^{\mathrm{a}}$ & $36.77 \pm 0.79^{\mathrm{b}}$ \\
GSH (nmol/g) & $08.44 \pm 0.28^{\mathrm{c}}$ & $03.65 \pm 0.18^{\mathrm{a}}$ & $09.42 \pm 0.26^{\mathrm{d}}$ & $06.71 \pm 0.24^{\mathrm{b}}$ \\
GPx (nmol/g) & $53.40 \pm 0.52^{\mathrm{c}}$ & $31.76 \pm 0.87^{\mathrm{a}}$ & $56.16 \pm 1.50^{\mathrm{c}}$ & $45.80 \pm 0.93^{\mathrm{b}}$ \\
SOD (U/mg) & $13.55 \pm 0.23^{\mathrm{b}}$ & $03.08 \pm 0.42^{\mathrm{a}}$ & $14.19 \pm 0.09^{\mathrm{b}}$ & $13.15 \pm 0.12^{\mathrm{b}}$ \\
\hline
\end{tabular}

Means values with different superscripts within the same row were significantly different at ( $\mathrm{p} \leq$ 0.05) (Mean \pm S.E.M) $(n=10)$. 


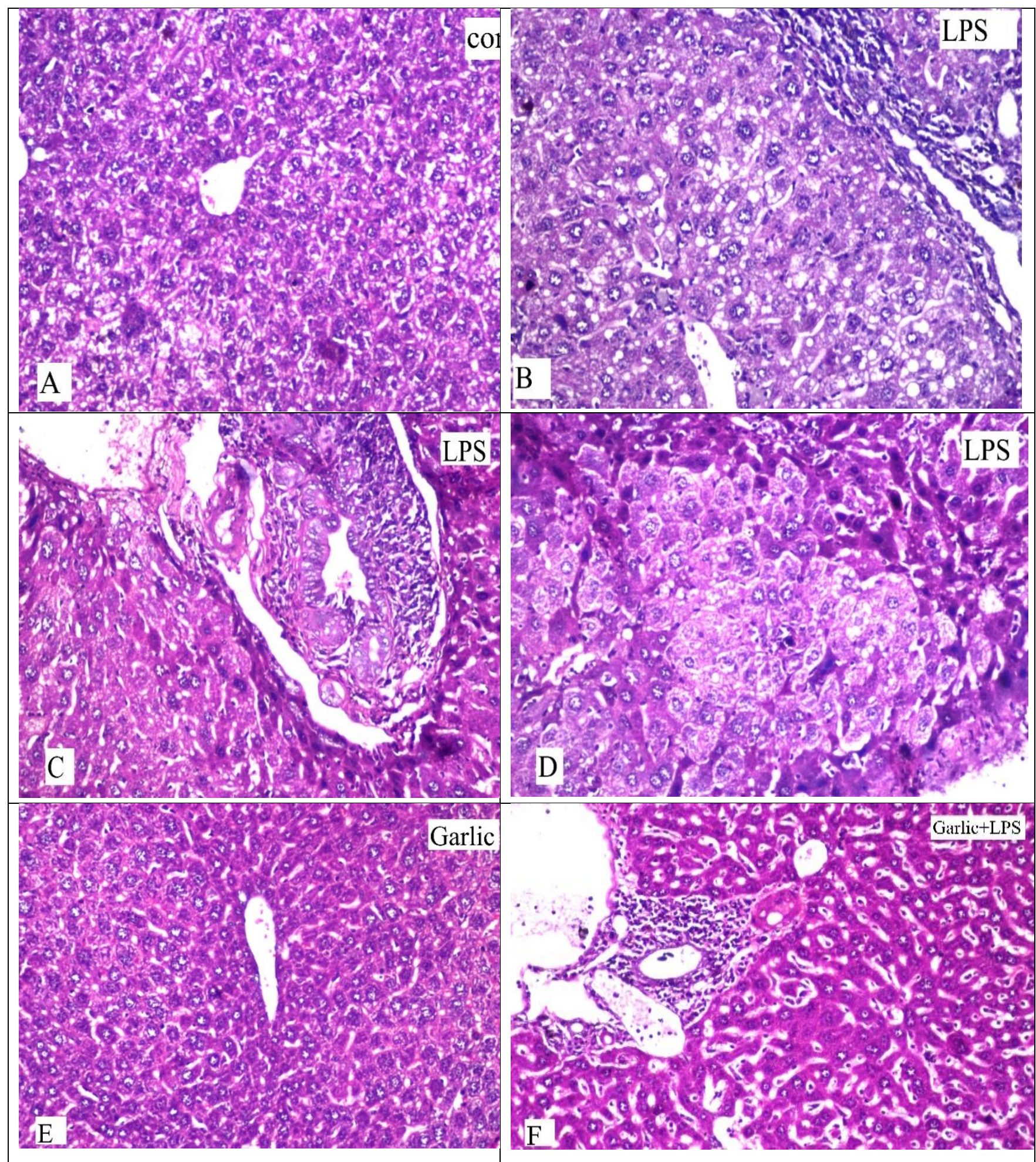

Figure 1. Histopathological examination of mice liver sections of different experimental groups. Liver sections of mice in LPS group showed fatty change in diffuse manner in the hepatocyte associated with inflammatory cells infiltration and fibrosis in the portal area (Figure 1. B). The bile duct in the portal area showed hyperplasia with periductal fibrosis and inflammatory cells infiltration (Figure 1.C). Focal areas in the hepatic parenchyma showed karyomegalocytes and ballooning degeneration. (Figure 1.D). While, in garlic protected group, there was periductal inflammatory cells infiltration surrounding the bile ducts associated with congestion of portal vein in the portal area (Figure 1.F). No histopathological alterations and the normal histological structure of the central vein and surrounding hepatocytes in the parenchyma were recorded in control (Figure 1.A) and garlic (Figure 1.E) groups. $40 \mathrm{X}$ magnification. 